\title{
EMPREENDEDORISMO SOCIAL: UM ESTUDO BIBLIOMÉTRICO DA PRODUÇÃO INTERNACIONAL
}

André Spuri Garcia ${ }^{1}$

Olívia Carolina De Resende Ribeiro ${ }^{2}$

Daniela Andrade ${ }^{3}$

João Paulo Nascimento Silva ${ }^{3}$

\footnotetext{
${ }^{1}$ Universidade Federal de Lavras (UFLA) - Universidade do Estado de Minas Gerais (UEMG)

${ }^{2}$ Pós-graduação em Administração / Universidade / UNIVERSIDADE POSITIVO

${ }^{3}$ Universidade Federal de Lavras
} 


\section{Empreendedorismo Social: Um estudo bibliométrico da produção internacional}

Resumo: O empreendedorismo social emerge como uma possível solução para os problemas sociais da sociedade contemporânea e parece ter se consolidado na prática sem que se tenha ainda uma precisão conceitual. Assim, por ser ainda um campo em construção, o empreendedorismo social precisa de aportes teóricos-metodológicos, fazendo-se necessário analisar o conceito na atual literatura. Dessa forma, este trabalho objetiva analisar como se configura a literatura internacional sobre empreendedorismo social através da busca pelo termo "social entrepreneurship" no título dos trabalhos na base de dados Web of Science através de uma análise bibliométrica e revisão de literatura. Foi observado que o campo ainda é recente, o que fica claro ao se observar as referências mais citadas e também a explosão do número de publicações apenas a partir de 2006 e também que as palavras-chaves mais citadas estão relacionadas com empreendedorismo privado, não identificando nenhuma instituição que possa ser considerada centro de referência.

Palavras-chave: Empreendedorismo social. Empreendedorismo. Bibliometria. Revisão de literatura. 


\section{Introdução}

O empreendedorismo social emerge como uma possível solução para os problemas sociais, passando pelas esferas econômicas, políticas e ambientais da sociedade contemporânea (SURIEN; GROEN, 2017; PARENTE et al, 2011). O empreendedorismo social parece ter se consolidado na prática sem que se tenha ainda uma precisão conceitual, o que acarretou uma linguagem nova, o termo do empreendedorismo social, mas a ocorrência do fenômeno certamente não é recente (DEES et al, 1998). Parente et al (2011, p. 269) colocam que isso causa uma inflação conceitual, isto é, "a falta de uma definição exata é acompanhada por um excesso de significado". Hulgard e Ferrarini (2010) afirmam que apesar de ainda ser um conceito novo e vago, o empreendedorismo social provou ser um importante veiculo de mudança social.

Adiante, Choi e Manjudar (2013) apontam que, nas últimas décadas, ocorreu um crescimento para o empreendedorismo social, tanto em termos teóricos quanto práticos. Segundo os autores, em termos práticos, tem sido uma ação estimulada por governos e pela iniciativa privada, já em termos teóricos tem sido objeto de estudo de vários centros e conta com eventos e periódicos dedicados a temática. Apesar do crescimento, alguns autores (CHOI; MANJUDAR, 2013; OLIVEIRA, 2004) colocam que o conceito de empreendedorismo social ainda não possui uma definição única, mas, pelo contrário, é um conceito contestado e com várias correntes teóricas concorrentes.

Apesar da não definição do conceito, o empreendedorismo social fica mais nítido quando comparado ao empreendedorismo privado (OLIVEIRA, 2004). Nesse sentido, é possível distinguir algumas características destes dois tipos de empreendimentos. Conforme apresentado por Oliveira (2004), o empreendedorismo social é coletivo e busca soluções para problemas sociais, enquanto o empreendedorismo privado é individual e tem foco no mercado. Dessa forma, compreende-se que enquanto a medida de desempenho do empreendedorismo privado é o lucro por ele gerado, o desempenho do empreendedorismo social é medido pelo impacto social e pelas mudanças sociais que ele produz (OLIVEIRA, 2004). Portanto, Oliveira (2004) coloca que onde o empreendedor privado vê clientes, o empreendedor social vê pessoas.

Assim, por ser ainda um campo em construção (OLIVEIRA, 2004), o empreendedorismo social precisa de aportes teóricos-metodológicos. Para tanto, faz-se necessário analisar o que já está colocado na literatura. Ainda, com o grande volume de eventos, periódicos e publicações que existem hoje em dia, revisões para mapear o estado da arte tornamse cada vez mais necessárias. Nesse sentido, este trabalho tem como objetivo analisar como se configura a literatura internacional sobre empreendedorismo social - social entrepreneurship. Para alcançar este objetivo utilizamos uma análise bibliométrica, que utiliza técnicas quantitativas para analisar a produção intelectual de um determinado campo cientifico. A partir disso, podem surgir insights importantes e que permitem uma análise qualitativa.

Além dessa introdução, o trabalho está dividido em mais quatro tópicos. Na sequência apresentamos o referencial teórico sobre empreendedorismo social. Adiante, a metodologia, onde buscou-se demonstrar de forma clara os passos utilizados para a realização da revisão bibliométrica - a metodologia tem como objetivo possibilitar a confirmação e replicação da bibliometria. Seguindo, o tópico de resultados e discussões foi dividido de forma a explorar os resultados tanto de forma quantitativa quanto de forma qualitativa. Assim, a etapa quantitativa
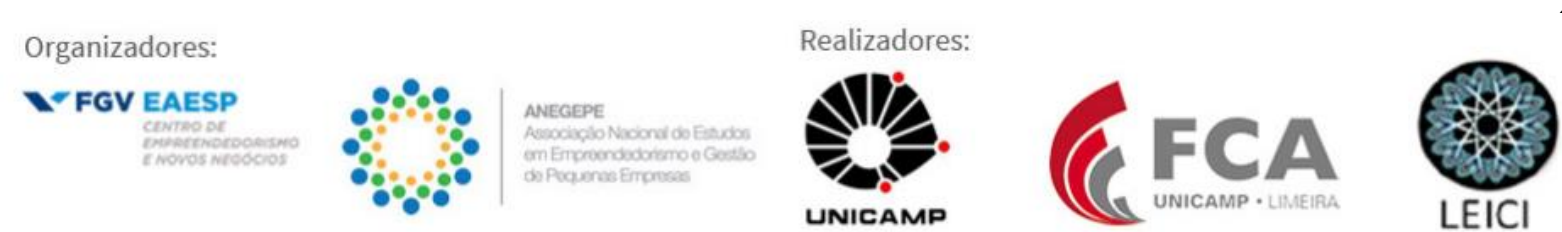
foi desenvolvida no formato de uma análise bibliométrica - o que não exclui aspectos qualitativos - e a etapa qualitativa buscou evidenciar as principais temáticas do campo. Por fim, as considerações finais com limitações e direcionamentos para novas pesquisas.

\title{
2 Referencial Teórico
}

Traduzindo o desejo de muitos brasileiros, o empreendedorismo, segundo o Relatório da Global Entrepeneurship Monitor - GEM (2015, 2016), tem sido visto como uma ferramenta que propicia o desenvolvimento econômico. Para Espejo e Previdelli (2006), o empreendedorismo gera impactos na sociedade, na economia, na política, produzindo empregos, gerando rendas, proporcionando crescimento e desenvolvimento (ESPEJO; PREVIDELLI, 2006). Dentre os conceitos iniciais acerca do empreendedorismo, os primeiros tiveram sua base nas teorias de desenvolvimento econômico, definindo-o como uma ação de agentes que promoviam mudanças.

\begin{abstract}
Aqueles indivíduos que utilizavam os recursos disponíveis de maneira diferenciada eram os agentes de transformação que rompiam com a estabilidade existente e obrigavam os demais agentes a se reorganizarem e se adaptarem às mudanças. Esse agente transformador, que promovia inovações, era chamado por Schumpeter (1934) de empreendedor. (STROBINO e TEIXEIRA, 2014, p. 60).
\end{abstract}

Além da corrente econômica, correntes da psicologia podem ser identificadas. Filion (1999), em seu estudo acerca do empreendedorismo, identificou duas correntes principais que tendem a conter elementos comuns à maioria das abordagens. A corrente dos economistas, que associa empreendedor à inovação, e a dos psicólogos, que enfatiza aspectos atitudinais. Gomes, Lima e Cappelle (2013, p.211), ao estudarem a caracterização da ação empreendedora pela recuperação de concepções de diferentes abordagens que se debruçaram no estudo do empreendedorismo, afirmam que "há definições notadamente influenciadas pelos economistas, outras de inspiração comportamentalista, e ainda existem aquelas que seriam, por assim dizer, um tanto quanto ecléticas.”. Segundo Gomes, Lima e Cappelle (2013), os comportamentalistas abordam o empreendedorismo a partir do sujeito que exerce a ação de empreender, traçando um "perfil psicológico" ou "comportamental" do empreendedor.

Para além destas correntes de pesquisa, mais recentemente emerge o Empreendedorismo Social como um tema embrionário nas ciências sociais e advém de uma associação entre o tradicional tema do empreendedorismo, desenvolvido no seio da economia e da gestão empresarial, e o recente tema das empresas sociais, emergente no quadro das problemáticas do terceiro setor (ou Economia Social) (QUINTÃO, 2004). Adiante, este fenômeno surge em contextos conjunturais de crises e desafios econômicos, sociais e ambientais. Weerawardena e Mort (2006) destacam que os empreendedores sociais, assim como os empreendedores privados, possuem características de liderança. Ainda, os autores destacam as diversas conceituações que o conceito de empreendedorismo social pode apresentar.

Alguns pesquisadores (Cook, Dodds, \& Mitchell, 2001; Wallace, 1999) sugerem que as empresas sociais que realizam atividades lucrativas para apoiar outras atividades
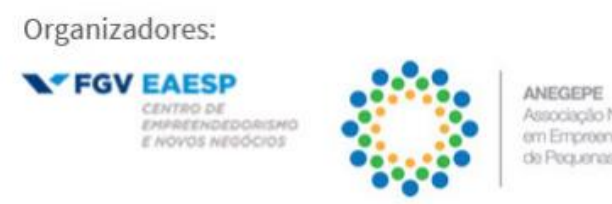

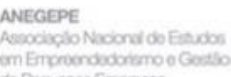
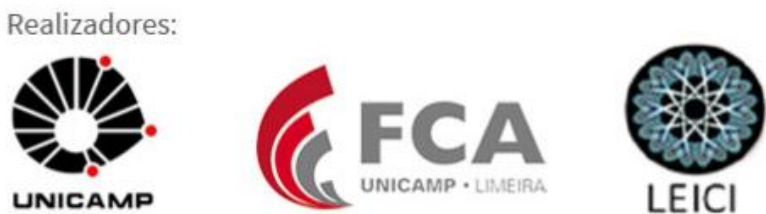
sem fins lucrativos podem ser vistas como empreendedores sociais. Outros argumentaram que as empresas lucrativas que podem levar alguma ação inovadora para a construção de capital social podem ser consideradas como socialmente empreendedoras (Centro Canadense de Empreendedorismo Social (CCSE), 2001, Thompson, Alvy e Lees, 2000). Thompson (2002) identifica o empreendedorismo social como possivelmente ocorrendo em empresas que buscam lucros que tenham algum compromisso de fazer o bem, nas empresas sociais criadas para um propósito social, mas operando como empresas e no setor voluntário ou sem fins lucrativos.

Zahra et al (2009, p. 520) ressaltam que os empreendedores sociais "desempenharam um papel vital na melhoria das condições sociais adversas, especialmente nas economias subdesenvolvidas e emergentes". Segundo os autores, nos países subdesenvolvidos a corrupção impede que a Administração Pública resolva os problemas necessários, o que faz com que existam mais empreendedores sociais. Os autores buscaram definir uma tipologia de empreendimento social e criaram três tipos que, conforme os próprios autores colocaram, não capturam todas as formas de empreendedorismo social. Os três tipos, segundos os autores, são: social bricoleur; social constructionists; social engineer. Os primeiros, segundo os autores, "Percebem e atuam sobre oportunidades para atender às necessidades sociais locais, são motivados e possuem a experiência e os recursos" (ZAHRA et al, 2009, p. 523). Já os segundos "Constroem e operam estruturas alternativas para fornecer bens e serviços atendendo às necessidades sociais que governos, agências e empresas não podem atender" (ZAHRA et al, 2009 , p. 523). Por fim, o terceiro tipo de empreendedorismo visa "a criação de sistemas sociais mais novos e mais eficazes projetados para substituir os existentes quando eles são inadequados para atender necessidades sociais significativas." (ZAHRA et al, 2009, p. 523)

Fischer e Comini (2012) destacam três correntes de pensamento sobre o empreendedorismo social: perspectiva europeia, americana e a linha que prevalece nos países em desenvolvimento. A corrente europeia enfatiza as ações das organizações da sociedade civil. A corrente americana diz respeito às empresas do setor privado agindo para resolver problemas sociais. Por fim, a terceira corrente "Enfatiza iniciativas de mercado que visam reduzir a pobreza e transformar as condições sociais das pessoas marginalizadas e excluídas." (FISCHER; COMINI, 2012, p. 367).

Para Choi e Majundar (2013), o conceito de empreendedorismo social é um conceito contestado, multifacetado e com várias definições concorrentes, o que gera uma fragmentação e dificulta o progresso da teoria - e, consequentemente, dificulta a concretização de perspectivas teórico-metodológicas para pesquisas empíricas. Choi e Manjudar (2013) citam, por exemplo, que para alguns pesquisadores o empreendedorismo social significa organizações sem fins lucrativos, enquanto para outros está relacionado com inovações sociais que tem por objetivo resolver problemas sociais. Diante disso, Choi e Manjudar (2013) ressaltam a dificuldade de estabelecer legitimidade enquanto campo de pesquisa. Além disso, os autores destacam que existe no campo uma disputa e, por isso, não há esforços para definição e unificação de um conceito. Corroborando com Choi e Manjudar (2013), Schneider (2017) coloca que existe uma confusão conceitual em relação ao empreendedorismo social, pois existem várias definições, muitas vezes conflitantes. Adiante, Nicholls (2010) coloca que não há, no campo do empreendedorismo social, um consenso paradigmático e epistemológico e também destaca a luta discursiva entre os vários autores.
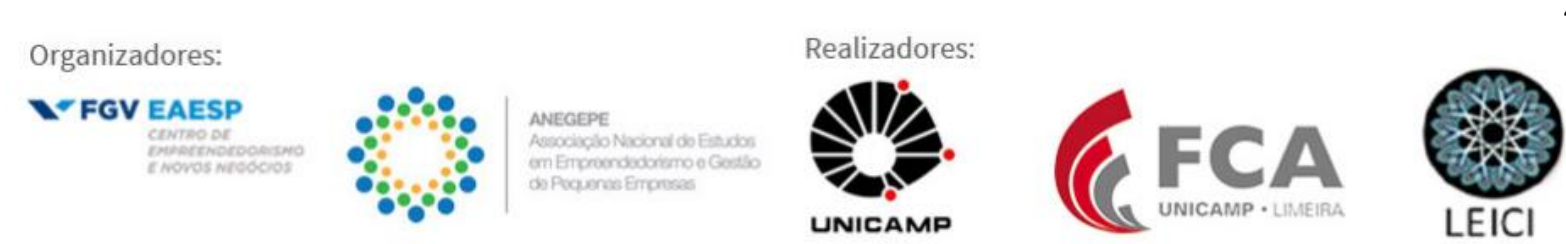
Choi e Manjudar (2013) colocam que o empreendedorismo social pode ser dividido em cinco subconjuntos, a saber: criação de valor social; o empreendedor social; a organização do empreendedorismo social; a orientação do mercado; e a inovação social. Nesse sentido, qualquer tentativa de definir ou qualquer pesquisa que tenha como objeto de estudo o empreendedorismo social deve perpassar ao menos um desses subconjuntos (CHOI; MANJUDAR, 2013). Nesse sentido, os autores argumentam que o empreendedorismo social pode ser conceituado através de cluster de subconceitos.

Phillips et al (2014) destacam o empreendedorismo social como algo que cria valor social em detrimento de riqueza pessoal, como observado no empreendedorismo privado. Ainda, os autores ressaltam que essa criação de valor social se dá pela inovação ou pela quebra de padrão - esta inovação pode ser de serviço, organizacional, entre outras. Assim, os autores não são tão rigorosos quanto ao conceito, pois a inovação social, na concepção dos autores, pode vir da própria iniciativa privada. Portanto, os autores vinculam o empreendedorismo social a qualquer inovação que resulte em ganhos sociais.

Young e Leci (2013) colocam que o consenso sobre o empreendedorismo social existe apenas em um nível alto de abstração. Segundo os autores, o consenso que existe é que o empreendedorismo social deve ter um propósito social - podendo, inclusive, combinar objetivos comerciais e sociais. Entretanto, os autores destacam que é difícil classificar e enquadrar o que seja propósito social. Assim, defendem a ideia de que o conceito não pode ser reduzido a uma única definição, mas sim admitir sua diversidade e complexidade. Segundo os autores, empreendedorismo social é uma mistura heterogênea de organização privada, governamental e sem fins lucrativos e ao "reconhecer a riqueza deste campo [...] os pesquisadores podem desenvolver de forma mais sistemática suas agendas de pesquisa e avançar para um nível de compreensão além dos esforços fragmentadas observados na literatura até então" (YOUNG; LECI, 2013, s/p.) Segundo Young e Leci (2013) essa seria uma vantagem do conceito de empreendedorismo social: abandonar a ideia de que benefícios sociais só podem ser gerados por organizações sem fins lucrativos e, mais que isso, que empreendimentos sociais não podem obter sucesso financeiro.

A partir do exposto, Young e Leci (2013) apresentam a metáfora do zoológico, ressaltando que o empreendedorismo social pode incorporar vários bichos, ou seja, vários tipos de organizações como empresas privadas com fins lucrativos, empresas sociais, cooperativas, organizações sem fins lucrativos, parceria público-privada e organizações híbridas. Portanto, os autores não argumentam em favor de uma definição rígida para o conceito de empreendedorismo social. Pelo contrário, argumentam que a vantagem do conceito é justamente poder incorporar diversas organizações com diversos tipos de estrutura.

Nicolopoulou (2014) destaca que o empreendedorismo social é um campo préparadigmático, sem abordagem metodológica e epistemológica dominante. Ainda, suas teorias são influenciadas pelas interações que o campo faz com o seu "campo raiz" (NICOLOPOULOU, 2014), isto é, o empreendedorismo, e também pelas interações que faz com domínios teóricos relacionadas com sustentabilidade, responsabilidade social, inovação, entre outros. Ainda segundo o autor, tentar observar o empreendedorismo social como um campo autônomo e paralelo em relação ao empreendedorismo privado tem prejudicado a discussão e sua consolidação teórica. Para o autor, o empreendedorismo social pode ser melhor entendido quando visto como uma modificação do empreendedorismo.
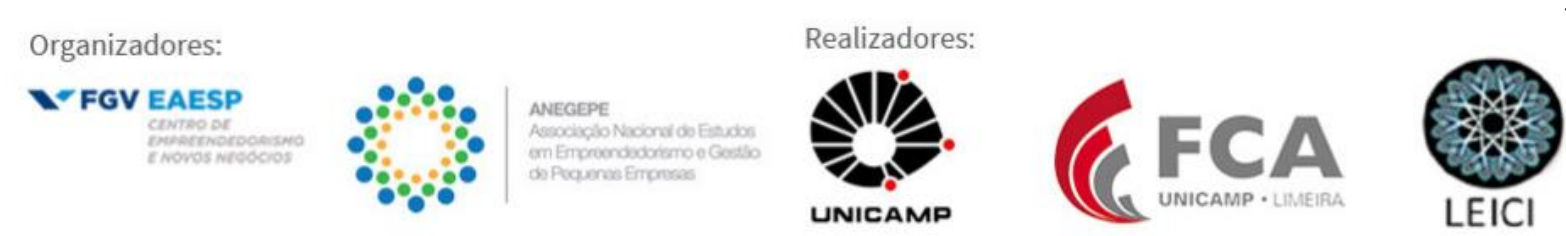
Chandra (2017) destaca o empreendedorismo social como uma forma de emancipação relação ainda não estudada com profundidade pela literatura (CHANDRA, 2017). Partindo de um conceito amplo de emancipação, o autor coloca que o empreendedorismo social pode ser uma forma de libertar o individuo de restrições ideológicas e de comportamentos estabelecidos no passado. Argumenta que o formato de organização não focado exclusivamente no lucro permite a emancipação para os envolvidos com o empreendimento.

\section{Metodologia}

Buscamos neste trabalho realizar uma revisão de literatura. Nesse sentido, a presente pesquisa se caracteriza como uma análise bibliométrica - uma dentre as várias técnicas de revisão de literatura disponíveis. Este tipo de análise emprega técnicas quantitativas que visam avaliar a produção acadêmica existente por meio das autorias, coautorias, citações, cocitações, periódicos, palavras-chaves, volume de publicações e distribuição da bibliografia (SANCHEZRIOFRIO; GUERRAS-MARTIN; FORCADELL, 2015). Ainda, Liu et al. (2014) colocam que a análise bibliométrica é um importante instrumento para avaliação da produção científica, isto é, para revisão da literatura, pois possibilita demonstrar a configuração, o desenvolvimento e a trajetória de um determinado campo científico ao longo do tempo.

\footnotetext{
Inicialmente voltada para a medida de livros (quantidade de edições e exemplares, quantidade de palavras contidas nos livros, espaço ocupado pelos livros nas bibliotecas, estatísticas relativas à indústria do livro), aos poucos foi se voltando para o estudo de outros formatos de produção bibliográfica, tais como artigos de periódicos e outros tipos de documentos, para depois ocupar-se, também, da produtividade de autores e do estudo de citações. (ARAÚJO, 2006, p. 12).
}

Como qualquer metodologia, a análise bibliométrica precisa clara em relação aos métodos utilizados para sua realização. Ainda, é importante que o estudo possa ser replicado e que seus resultados possam ser comprovados por quaisquer outros pesquisadores principalmente dado ser caráter quantitativo. Diante disso, utilizamos nesse trabalho uma adaptação do framework de pesquisa utilizado por Prado et al. (2016). Esse framework descrever algumas etapas a serem seguidas pelo pesquisador para planejamento do estudo. Estas etapas estão relacionadas com a busca de dados, seleção, organização e análise do material que constituirá o corpus do estudo. Importante destacar que os passos elaborados por Prado et al (2016) não são necessariamente lineares, possibilitando assim a realimentação do processo.

Para a primeira etapa da construção da pesquisa bibliométrica é importante definir os termos de busca e a base na qual esta busca será realizada. Neste trabalho utilizamos definimos como objeto de estudo o campo do Social Entrepreneurship e, portanto, utilizamos a base de dados da Web of Science (coleção principal) da Thomson Reuters Scientific para realizar o levantamento dos artigos. A escolha por uma única base de dados, seguindo a recomendação de Prado et al (2016), se deve à padronização das informações levantadas. Quanto a base escolhida, destacamos sua relevância, abrangência e confiabilidade, que atualmente fornece acesso a mais de 12.000 das principais revistas acadêmicas e científicas de todo o mundo

\section{Organizadores:}
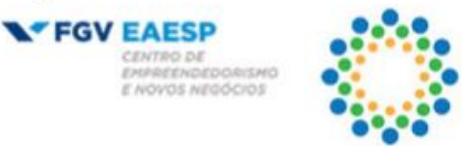

ANEGEPE Associapio

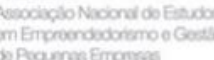
Theres Emproses
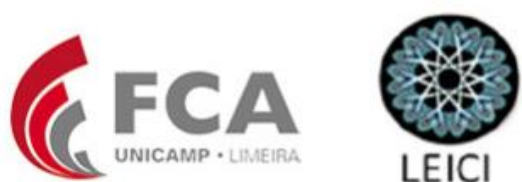
(PINTO; SERRA; FERREIRA, 2014). Mais especificamente em relação a bibliometria - e o software comumente utilizado para realizá-la - a base possibilita que se faça exportações das buscas e referências para a utilização do software de análise bibliométrica CiteSpace (CHEN, 2004, 2006), o qual será utilizado neste trabalho. Este software proporciona a construção do Chen (2006) chama de Research front (os trabalhos mais citados de um campo científico, que possui um caráter transitório, pois novos artigos podem substituir os artigos existentes), bem como Intellectual base (as citações e cocitações na literatura científica, que evoluem como uma rede de publicações científicas citadas pelos artigos da frente de pesquisa). Ambos os conceitos são importantes para verificar tendências e padrões transitórios na literatura científica de um determinado campo de conhecimento (CHEN, 2006).

Para a realização da busca utilizamos o termo "social entrepreneurship" - entre aspas, com o intuito de aparecer o termo inteiro. O termo buscado deveria constar no título dos artigos. Foram considerados todos os anos da base até 2017 - último ano completo - assim como todos os idiomas, todas as categorias, todos os formatos de trabalho, etc. Assim, a busca não foi feita com nenhum filtro específico. Essa busca resultou em 476 artigos. Adiante, para utilização do CiteSpace realizamos o download das referências dos artigos e das referências citadas por eles, que foram exportadas em formato de planilha eletrônica para tabulação e também em formato de texto para o software CiteSpace (CHEN, 2004, 2006).

A análise da Research front consiste em analisar os 476 trabalhos encontrados na busca. Nesse sentido, realizamos inicialmente uma análise do volume temporal das publicações para verificar o seu início e se existem tendências no volume - ou seja, picos ou quedas de publicações ao longo dos anos. Ressaltamos que o mais importante nesta etapa consiste na análise de citações dos artigos selecionados, pois é por meio desse resultado que se podem definir os trabalhos que representam as principais temáticas tratadas pelo "campo". Ainda realiza-se a análise das palavras-chaves. Para operacionalizar essa etapa foram realizadas análises das informações levantadas na Web ofScience com a utilização do Software CiteSpace.

Por sua vez, a análise da Intellectual base de uma frente de pesquisa nos mostra as citações e cocitações na literatura científica (CHEN, 2006). A principal contribuição dessa etapa é a análise das referências utilizadas pela amostra encontrada, o que possibilita expandir os resultados possíveis para além da base pesquisada. Assim, ressaltamos que os trabalhos da Intellectual base não são, necessariamente, os mesmos trabalhos localizados pela busca inicial na base de pesquisa escolhida.

A operacionalização dessa etapa é realizada por meio da inserção dos dados coletados na Web of Science no software CiteSpace. Adiante, realiza-se a análise das frequências de cocitações da amostra, bem como suas respectivas citações na base Web of Science com intuito de verificar a relevância da Intellectual base encontrada.

\section{Resultados e Discussões}

Inicialmente apresentamos a frequência de publicações por ano (Gráfico 1). Por meio do gráfico é possível observar que estudos sobre empreendedorismo social são recentes. Apesar de o primeiro trabalho da busca ter sido publicado em 1988, até 2005 o número de publicações era bastante baixo. A partir de 2006 o número de publicações aumenta consideravelmente, atingindo o ápice em 2016 (113 trabalhos publicados). Aspecto interessante é que, segundo

\section{Organizadores:}

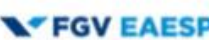

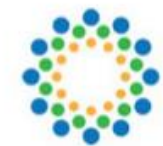
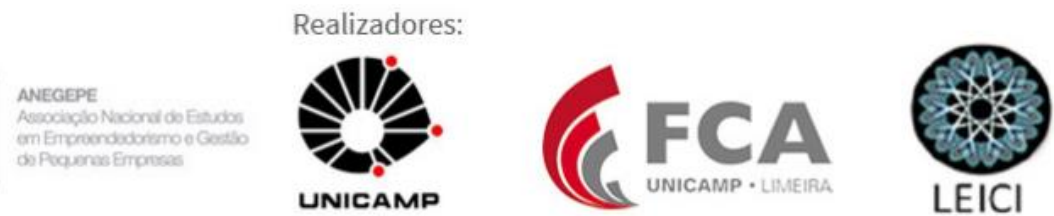
Oliveira (2004), o empreendedorismo social emerge na década de 1990 diante dos cortes de gastos observados no setor público e das diversas problemáticas existentes. Além disso, as discussões sobre terceiro setor também emergem nesse contexto. Assim, existe um intervalo de tempo entre o surgimento do empreendedorismo social e sua utilização no meio acadêmico.

\section{Gráfico 1 - Número de publicações por anos}

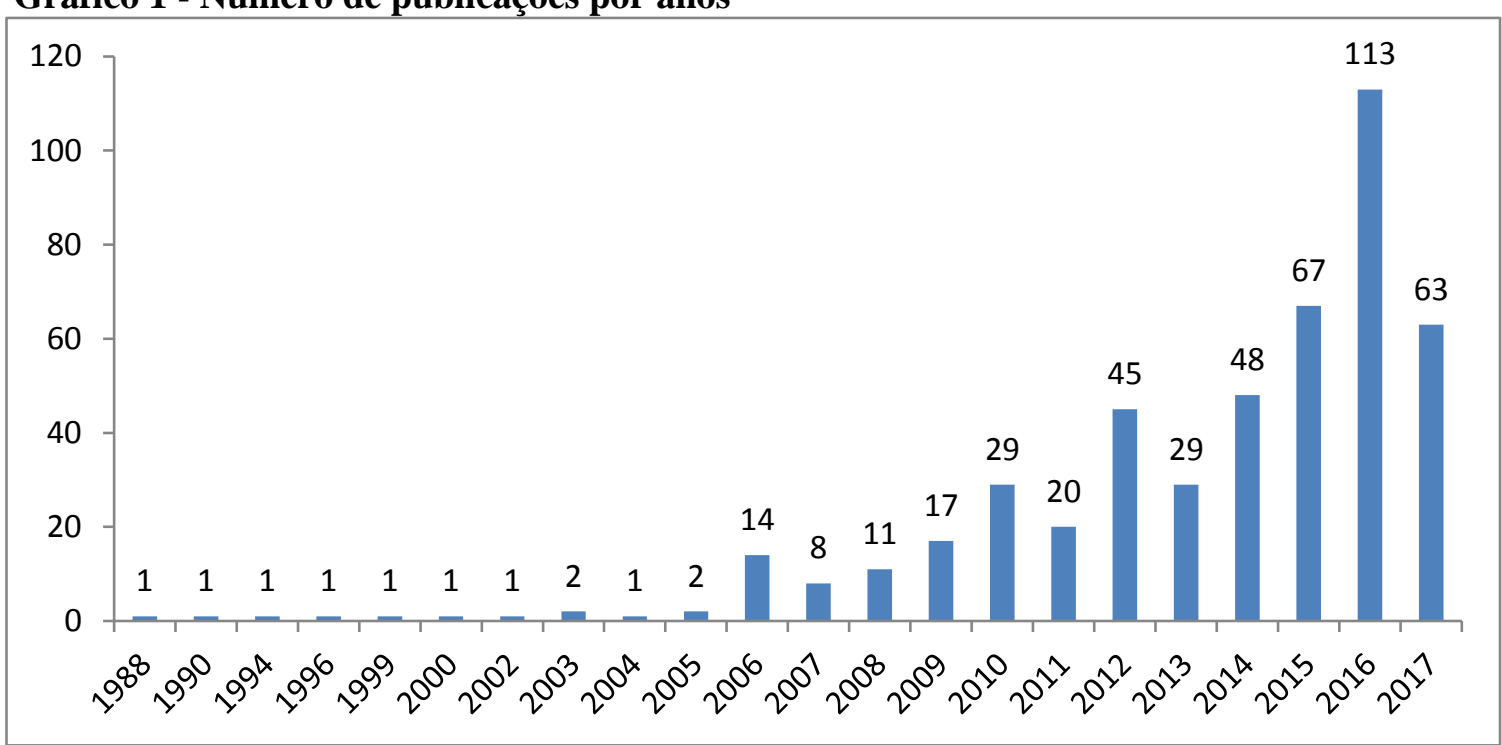

Fonte: elaborado pelos autores a partir da Web Of Science

Na sequência, a Figura 1 apresenta as palavras-chaves mais citadas, a saber: social entrepreneurship (263 citações); innovation (43 citações); enterprise (40); social enterprise (38 cit.); business (32); enterprise (32); entrepreneurship (32); organizations (26); social innovation (24); responsibility (23); opportunities (23);; management (22). As palavras-chaves mais utilizadas não dizem muito sobre empreendedorismo social, pois estão mais relacionadas com as derivações do termo empreendedorismo e algumas estão mais ligadas ao empreendedorismo privado (management, business). Entretanto, é possível levantar algumas hipóteses. A palavra organizations, por exemplo, pode estar relacionada à organizações do terceiro setor ou organizações privadas já que, conforme encontramos na literatura, são várias as organizações que podem realizar empreendimentos sociais ou mesmo inovações sociais. Ainda nesse sentido, o fato de aparecer variações do termo empreendedorismo nos remete a uma idéia de que o conceito ainda não é bem definido. Uma possível causa é justamente a diversidade de autores e organizações que podem realizar empreendimentos sociais, o que causa uma certa dificuldade de definição. 
Figura 1 - Palavras-chaves mais citadas

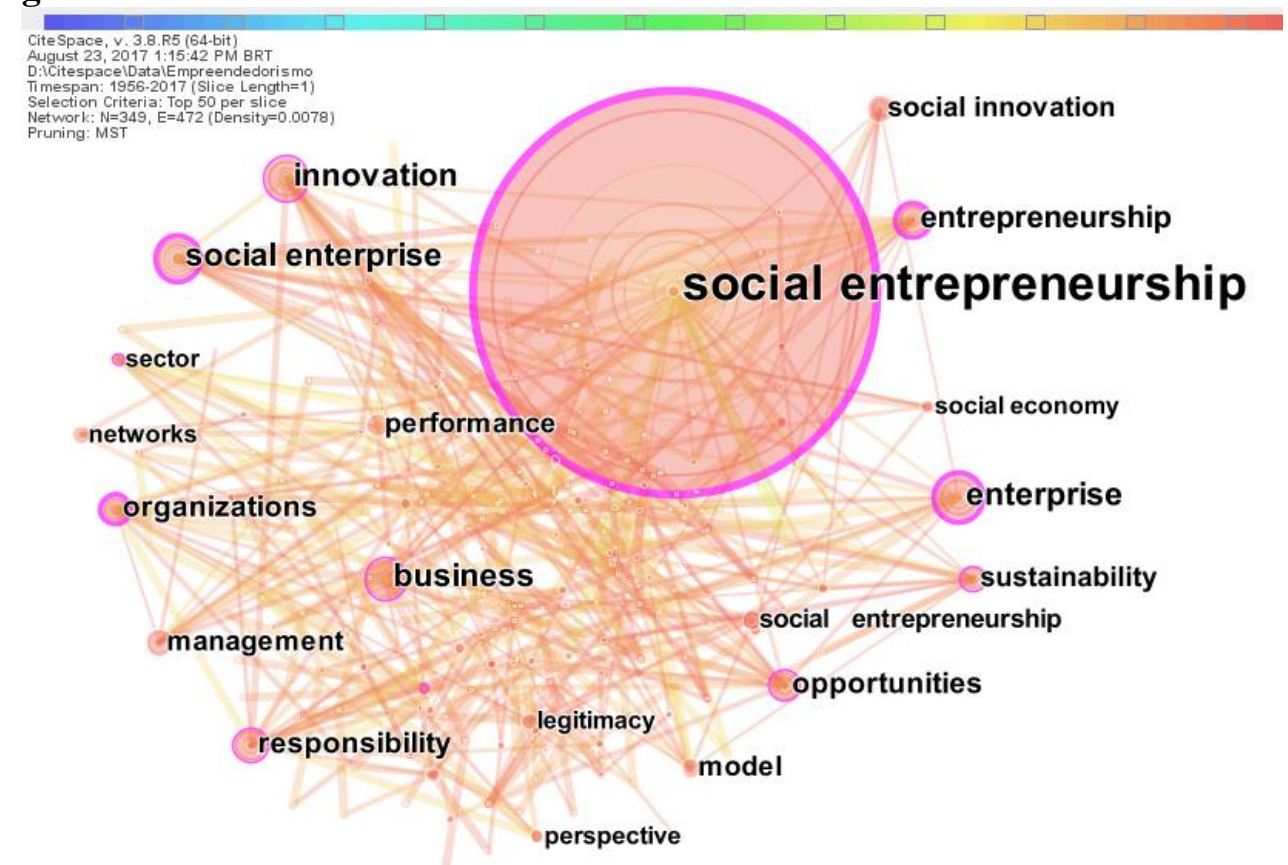

Fonte: Elaborado pelos autores a partir do CiteSpace

Adiante, algumas outras palavras que aparecem na rede (Figura 1) podem nos dizer algo sobre o conceito de empreendedorismo social - ou criar algumas hipóteses. A palavra sustainability, por exemplo, pode estar relacionada com empreendimentos sociais relacionados com questões ambientais. A palavra social economy mostra o caráter não lucrativo destes empreendimentos. O termo innovation - muito utilizado em empreendedorismo privado - pode nos dizer que mesmo sendo um empreendimento social e sem fim lucrativo os empreendimentos sociais podem gerar inovação - principalmente no sentido de inovação social (SURIEN; GROEN, 2017).

Adiante, a Figura 2 mostra em quais categorias da Web of Science os artigos sobre empreendedorismo social estão indexados. Assim, a Figura 2 apresenta as dez categorias com maior número de artigos sobre o empreendedorismo social. A análise de categorias permite inferir em qual campo científico (filosofia, ciências sociais, administração, entre tantos outros) determinado tema está sendo mais desenvolvido. Além disso, por meio de uma time zone (recurso disponível pelo (CiteSpace) é possível observar em qual categoria o termo surgiu e como ele foi, ao longo do tempo, aparecendo em outras categorias e em outros campos científicos. Assim, as categorias com maior número de artigos foram: Business \& Economics (315 trabalhos); Business (224); Management (150); Economics (62); Public Administration (50); Social Science (44); Education \& Educational Research (40); Planning \& Development (31); Social Issues (25); Ethics (18). Assim, observa-se que a grande maioria dos trabalhos está em categorias relacionadas a negócio e economia - o que era esperado, pois, apesar de tratar de questões sociais, o termo surge da questão do empreendedorismo, campo naturalmente relacionado à Administração e Economia.

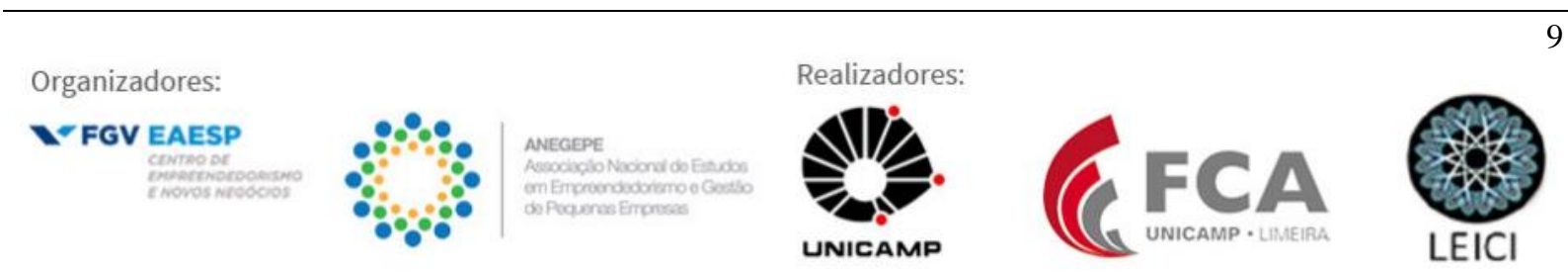


Figura 2 - Categorias com maior número de trabalhos sobre empreendedorismo social .

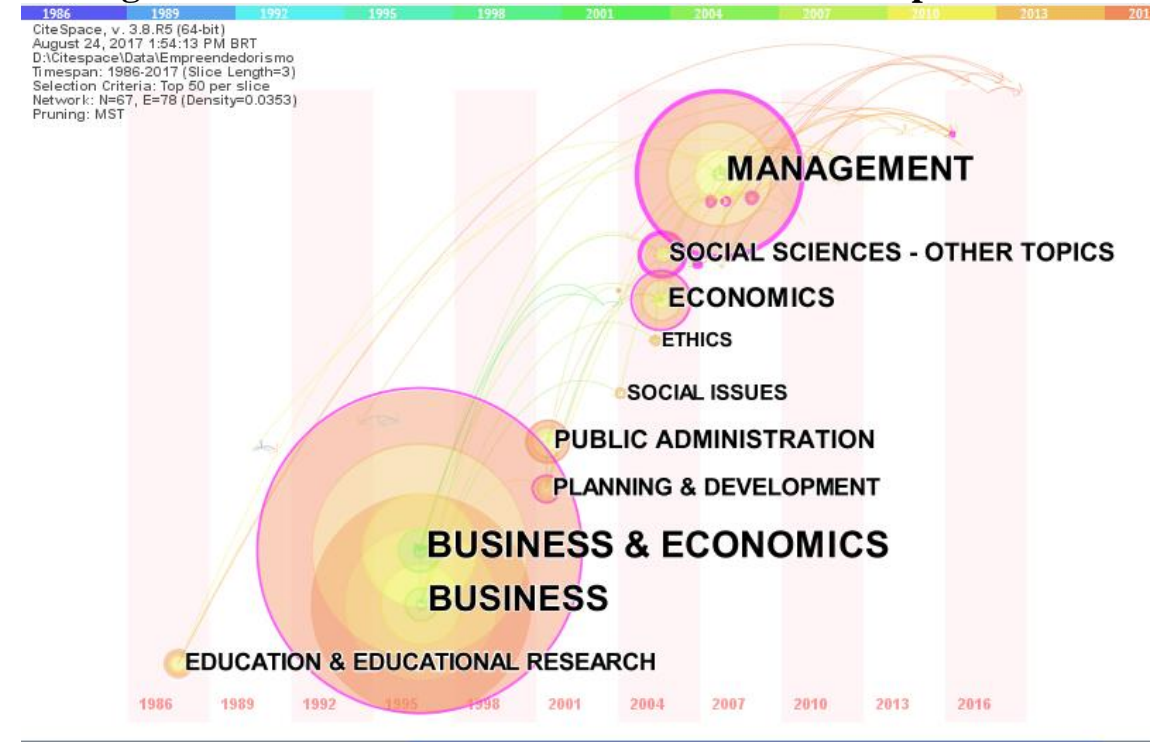

Fonte: Elaborado pelos autores a partir do CiteSpace

Assim, por meio da Figura 2 é possível perceber que o tema surgiu na categoria Education \& Educational Research com o trabalho The Rapids Change: Social Entrepreneurship in Turbulent Times (THEOBALD, 1988). Nesta obra o autor discorre sobre as diversas mudanças pelas quais a sociedade vinha passando naquela época - mudanças tecnológicas, ambientais, políticas, econômicas, entre outras. Segundo o autor, as instituições não seriam capazes de lidar com essas demandas, o que exigiria cada vez mais a ação de empreendedores social (THEOBALD, 1988). Importante observar também que o tema surgiu primeiro nas categorias relacionadas com Administração e Economia, e só depois apareceu em categorias como Administração Pública, Ciências Sociais, entre outras.

Em relação aos países com maior número de artigos - esta análise está relacionada com a nacionalidade de origem dos autores, e não necessariamente com o lugar físico onde os artigos foram produzidos - destacam-se: Estados Unidos (126 trabalhos), Inglaterra (39), Espanha (29), China (24), Canadá (24), Romênia (18), Austrália (13), República Checa (13); Índia (12), Alemanha (12). Nesse sentido, existe uma discrepância grande dos Estados Unidos em relação à produção acadêmica sobre empreendedorismo social. O Brasil apresenta apenas seis trabalhos, o que demonstra a nossa pouca publicação internacional sobre o tema (Tabela 1). Em relação às instituições, não se observou nenhum grande destaque, isto é, alguma instituição que pudesse ser considerada um centro de pesquisa sobre empreendedorismo social.

Tabela 1 - Artigos de autores brasileiros

\begin{tabular}{|c|c|c|c|}
\hline Título & Autores & Ano & Cit. \\
\hline $\begin{array}{l}\text { Research discourses on entrepreneurship and social } \\
\text { entrepreneurship in digital media: a critical analysis }\end{array}$ & Casaqui, V. & 2017 & 0 \\
\hline $\begin{array}{l}\text { Scalability: Concept, Characteristics And Chalenges Since The } \\
\text { Commercial And Social Entrepreneurship }\end{array}$ & $\begin{array}{l}\text { Cavazos-Arroyo, J; } \\
\text { Giuliani, A. C. }\end{array}$ & 2017 & 0 \\
\hline $\begin{array}{l}\text { Entrepreneurial Education: The Development of Social } \\
\text { Entrepreneurship and Innovatio in Higher Education Institutions }\end{array}$ & Miranda et al. & 2016 & 0 \\
\hline
\end{tabular}


Systematic Review Of The Literature Social Entrepreneurship And Skills Development: An Analysis Of The Past 10 Years

Social entrepreneurship and social business: retrospective and prospective research

Innovation in Social Entrepreneurship: The Economy of Communion in Freedom (Eoc)

Fonte: Elaborado pelos autores

Em relação aos periódicos, a Tabela 2 apresenta aqueles que mais publicaram trabalhos da amostra. A análise de periódicos é importante, pois mostra se determinado journal é referência em determinada temática, o que indicaria um caminho para buscas de referencial sobre determinada temática. Nota-se (Tabela 2) que não existe uma grande discrepância de um determinado periódico, mas no conjunto os journals da tabela abaixo formam um conjunto interessante de fonte de dados para os pesquisadores que buscam estudar empreendedorismo social.

Tabela 2 Periódicos que mais publicaram os artigos da frente de pesquisa.

\begin{tabular}{l|r}
\hline Periódico & Freq. \\
\hline Journal of Business Ethics & 14 \\
\hline Academy of Management Learning Education & 12 \\
\hline Voluntas & 12 \\
\hline Entrepreneurship and Regional Development & 11 \\
\hline Journal of Social Entrepreneurship & 11 \\
\hline Proceedings of the European Conferenceon Entrepreneurship and Innovation & 10 \\
\hline International Small Business Journal & 9 \\
\hline Procedia Social and Behavioral Sciences & 8 \\
\hline International Journal of Contemporary Hospitality Management & 9 \\
\hline Social Entrepreneurship Book & 6 \\
\hline
\end{tabular}

Fonte: Elaborado pelos autores a partir da Web Of Science

Adiante, um dos resultados relevantes para este estudo, no que se refere ao Research front, é a identificação dos artigos mais citados que compõem a amostra retirada da Web of Science. Estes artigos podem demonstrar os temas mais relevantes dentro de um campo, além de trazer definições importantes. Neste sentido, a Tabela 3 apresenta os artigos mais citados da frente de pesquisa e, na sequência, discorremos brevemente sobre os três mais citados.

Tabela 3 - Artigos mais citados da frente de pesquisa.

\begin{tabular}{|c|c|c|c|}
\hline Título & Autores & Ano & Cit. \\
\hline $\begin{array}{l}\text { Social entrepreneurship research: A source of explanation, prediction, } \\
\text { and delight }\end{array}$ & Mair, J; Marti, I & 2006 & 748 \\
\hline Social entrepreneurship: A critical review of the concept & $\begin{array}{l}\text { Peredo, AM; McLean, } \\
\text { M }\end{array}$ & 2006 & 391 \\
\hline Investigating social entrepreneurship: A multidimensional model & $\begin{array}{l}\text { Weerawardena, J; Mort, } \\
\text { GS }\end{array}$ & 2006 & 301 \\
\hline $\begin{array}{l}\text { Research In Social Entrepreneurship: Past Contributions And Future } \\
\text { Opportunities }\end{array}$ & $\begin{array}{l}\text { Short, J. C.; Moss, T. } \\
\text { W.; Lumpkin, G. T. }\end{array}$ & 2009 & 281 \\
\hline
\end{tabular}


Social Entrepreneurship: Why We Don't Need a New Theory and How We Move Forward From Here

The Legitimacy of Social Entrepreneurship: Reflexive isomorphism in a Pre-Paradigmatic Field

Social Entrepreneurship: A Critique and Future Directions

A Positive Theory of Social Entrepreneurship

Personal values as a catalyst for corporate social entrepreneurship

Venturing For Others With Heart And Head: How Compassion

Encourages Social Entrepreneurship

Fonte: Elaborado pelos autores a partir da Web Of Science

Mair e Martí (2006) afirmam que o conceito de empreendedorismo social significa coisas diferentes para diferentes pessoas e pesquisadores. Sendo entendido como: iniciativas sem fins lucrativos em busca de estratégias de financiamento alternativas ou esquemas de gestão para criar valor social; prática socialmente responsável das empresas comerciais envolvidas em parcerias entre setores; e um meio para aliviar os problemas sociais e potencializar a transformação social. Assim, é possível perceber que o empreendedorismo social é relacionada a diversos tipos de organizações.

Adiante, os autores colocam que empreendedorismo social é amplo, mas pode ser entendido como um processo que envolve captação de recursos para buscar oportunidades e potencializar mudanças sociais e atender às necessidades sociais. Mair e Martí, (2006) apresentam algumas premissas básicas:

o empreendedorismo social é um processo de criação de valor, combinando recursos de novas maneiras, além disso, essas combinações de recursos destinam-se principalmente a explorar oportunidades para criar valor social estimulando a mudança social ou atendendo às necessidades sociais e por fim, quando visto como um processo, o empreendedorismo social envolve a oferta de serviços e produtos, mas também pode se referir à criação de novas organizações. (MAIR; MARTÍ, 2006, p. 37)

Assim Mair e Martí (2006), vislumbrando o empreendedorismo social como um processo resultante da interação contínua entre empresários sociais e o contexto em que eles e suas atividades estão integradas, reúnem ideias da sociologia, da ciência política e da teoria da organização para enriquecer nossa compreensão teórica do assunto.

Peredo e McLea (2006) afirmam em seu trabalho que existe um amplo acordo de que os empreendedores sociais e seus empreendimentos são impulsionados por objetivos sociais, isto é, o desejo de beneficiar a sociedade de alguma maneira. Esta é outra maneira de dizer que o empreendedor social visa de alguma forma aumentar o "valor social", ou seja, contribuir para o bem-estar em uma determinada comunidade.

Por sua vez, Weerawardena e Mort (2006) buscaram contribuir para a construção do conceito de empreendedorismo social. A partir da ideia de grouded theory os autores analisaram estudos empíricos sobre empreendedorismo social e, a partir desta análise, buscaram definir o conceito. Assim, os autores apresentam algumas proposições sobre o que seja empreendedorismo social e colocam que "o empreendedorismo social é uma construção
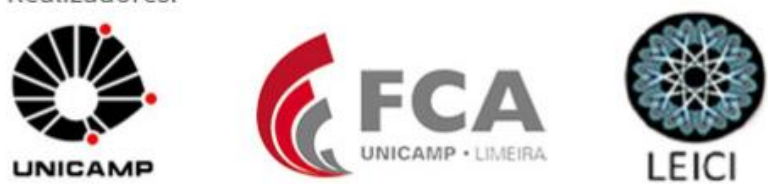
multidimensional delimitada que está profundamente enraizada na missão social de uma organização, sua unidade de sustentabilidade e altamente influenciada e moldada pela dinâmica ambiental." (WEERAWARDENA; MORT, 2006, p. 22). Ainda, destacam que os empreendimentos sociais precisam criar uma cultura de inovação, proatividade e de gerenciamento de riscos. Outro aspecto interessante observado pelos autores é a crescente concorrência entre empreendimentos solidários para captar recursos - dos mais variados tipos. Neste sentido, estas empresas tendem a agir cada vez mais como empresas privadas - o que, segundo a teoria crítica das organizações, é problemático, pois contamina estas organizações com a lógica de mercado (TENÓRIO, 1999, 2005).

Em relação a base intelectual, isto é, as referências utilizadas pelos artigos da frente de pesquisa (Tabela 4), percebe-se que os trabalhos mais referenciados são recentes. Dos dez trabalhos mais referenciados, nove foram publicados a partir de 2004. Isso evidencia um campo novo e ainda em construção - o que corrobora com a sua falta de definição. Corroborando com esta assertiva, Oliveira (2004, p. 10) coloca que "o tema empreendedorismo social é novo em sua atual configuração, mas na sua essência já existe há muito tempo.”. Assim, o empreendimento social parece ter se configurado na prática antes mesmo do que na teoria.

Tabela 4 - Base Intelectual - Obras mais referenciadas pelos artigos da frente de pesquisa

\begin{tabular}{l|l|r|r}
\hline Autores & Título & Ano & Cit. \\
\hline Mair, J., and I. Marti & $\begin{array}{l}\text { Social entrepreneurship research: A source of explanation, } \\
\text { prediction and delight. }\end{array}$ & 2006 & 146 \\
\hline $\begin{array}{l}\text { Austin, J., Stevenson, } \\
\text { H., \&Wei-Skillern, J. }\end{array}$ & Social and commercial entrepreneurship: Same, different, or both? & 2006 & 124 \\
\hline $\begin{array}{l}\text { Peredo, A. M., } \\
\text { \&McLean, M. }\end{array}$ & Social entrepreneurship: A critical review of the concept. & 2006 & 90 \\
\hline $\begin{array}{l}\text { Zahra, S. A., Gedajlovic, } \\
\text { E., Neubaum, D. O., } \\
\text { \&Shulman, J. M. }\end{array}$ & $\begin{array}{l}\text { A typology of social entrepreneurs: Motives, search processes and } \\
\text { ethical challenges. }\end{array}$ & \\
\hline $\begin{array}{l}\text { Alvord, S.H., L.D. } \\
\text { Brown, and C.W. Letts. }\end{array}$ & $\begin{array}{l}\text { Social entrepreneurship and social transformation: An exploratory } \\
\text { study. }\end{array}$ & 2009 & 85 \\
\hline $\begin{array}{l}\text { Dacin, P. A., Dacin, M. } \\
\text { T., \& Matear, M. }\end{array}$ & $\begin{array}{l}\text { Social entrepreneurship: Why we don't need a new theory and how } \\
\text { we move forward from here. }\end{array}$ & 2004 & 66 \\
\hline $\begin{array}{l}\text { Short, J. C., Moss, T. } \\
\text { W., \& Lumpkin, G. T. }\end{array}$ & $\begin{array}{l}\text { Research in social entrepreneurship: Past contributions and future } \\
\text { opportunities }\end{array}$ & 2010 & 63 \\
\hline $\begin{array}{l}\text { Weerawardena, J., \& } \\
\text { Mort, G. S. }\end{array}$ & Investigating social entrepreneurship: A multidimensional model. & 2006 & 62 \\
\hline Dees, J. G. & The meaning of “social entrepreneurship.” & 1998 & 58 \\
\hline \begin{tabular}{l} 
Seelos, C., \& Mair, J. \\
\hline
\end{tabular} & $\begin{array}{l}\text { Social entrepreneurship: Creating new business models to serve the } \\
\text { poor. }\end{array}$ & 2009 & 63 \\
\hline
\end{tabular}

Fonte: Elaborado pelos autores a partir do CiteSpace

Diferente de outros campos do conhecimento, que possuem obras centrais publicadas ainda no século passado, o empreendedorismo social ainda não possui obras centrais com grande número de referências. Outro aspecto interessante é que dentre as obras mais referencias não há nenhuma que trate do empreendedorismo privado. Todas as obras possuem empreendedorismo social logo no título. Isso parece indicar que o empreendedorismo social pode estar se desprendendo do empreendedorismo privado.

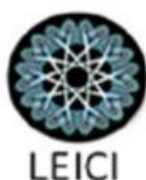


Tabela 5 - Autores mais citados pela frente de pesquisa

\begin{tabular}{l|l}
\hline Autores & Citações \\
\hline Johanna Mair & 189 \\
\hline James Austin & 143 \\
\hline Gregory Dees & 139 \\
\hline Shalker Zahra & 109 \\
\hline Alex Nicholls & 107 \\
\hline Ana Maria Peredo & 99 \\
\hline David Bornstein & 95 \\
\hline Jay Weerawardena & 84 \\
\hline John L. Thompson & 71 \\
\hline Sarah H. Alvord & 67 \\
\hline Fonte: Elaborado pelos autores a partir do CiteSpace
\end{tabular}

Adiante, para analisar a base intelectual de um determinado campo é necessário olhar quais são os autores mais referenciados (citados) pelos artigos que compõem a amostra (frente de pesquisa). Nesse sentido, a Tabela 5 apresenta os autores mais citados pela frente de pesquisa. Nota-se, novamente, a importância Johanna Mair. A autora possui a obra mais referenciada do campo, o trabalho mais citado da frente de pesquisa e é também a autora mais citada. Neste sentido, ao se falar sobre empreendedorismo social é necessário recorrer aos estudos de Johanna Mair. Além dela, outros autores figuram como importantes tanto na frente de pesquisa como também na base intelectual. Esse aspecto reforça o argumento de um campo novo e em construção. Em campos mais consolidados os autores da base intelectual costumam ser clássicos, mais antigos e diferentes daqueles que compõem a frente de pesquisa (GARCIA, 2016).

\section{Considerações Finais}

Este trabalho buscou analisar como se configura a literatura sobre empreendedorismo social - social entrepreneurship. Por ser um campo ainda recente - e a nossa bibliometria elucidou isso - é necessário investigar como (e por quem) o tema tem sido tratado na academia. Além disso, o grande volume de publicações e informações disponível hoje em dia torna cada vez mais relevantes pesquisas que busquem elucidar o estado da arte - qualitativo ou quantitativo - dos campos de conhecimento.

Para alcançar o objetivo proposto utilizamos uma análise bibliométrica - um dentre vários tipos de revisão de literatura. Este tipo de revisão de literatura tem um caráter mais quantitativo, mapeando autores mais citados, periódicos que mais publicam, entre outros aspectos. Isso não impossibilita, entretanto, que sejam feitas algumas análises (breves insights) qualitativos.

Assim, em síntese observamos que o campo ainda é recente, o que fica claro ao se observar o quão recente são as referencias mais citadas (a base intelectual) e também a explosão do número de publicações apenas a partir de 2006. Ainda, observamos que as palavras-chaves mais citadas estão relacionadas com empreendedorismo privado, mas ao analisar as referencias mais citadas observa-se uma tendência de separação entre empreendedorismo público e privado, com o primeiro consolidando uma literatura própria. Em relação aos países, observamos grande predominância dos Estados Unidos como produtor de trabalhos sobre

\section{Organizadores:}

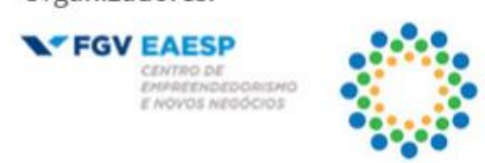

Realizadores:

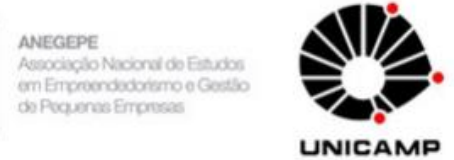


empreendedorismo social. Entretanto, não identificamos nenhuma instituição específica que possa ser considerada centro de referencia.

Como limitação, destacamos que nosso trabalho utilizou apenas uma base de dados apesar de sua grande relevância, usar apenas uma base pode ser visto como limitação. Ainda, nossa análise foi - coerente com o método aplicado - quantitativa, o que pode limitar os resultados. Nesse sentido, sugerimos como agenda de pesquisa revisões de literatura de caráter qualitativo. Sugerimos ainda que sejam feitas revisões mais voltadas para o âmbito nacional, no intuito de verificar o que a academia brasileira vem escrevendo sobre empreendedorismo social. Além disso, é importante observar a agenda de pesquisa dos artigos mais recentes para identificar para onde o campo do empreendedorismo social deve caminhar nos próximos anos.

\section{Referências Bibliográficas}

ARAÚJO, C. A. Bibliometria: evolução histórica e questões atuais. Em questão, v. 12, n. 1, 2006.

CHANDRA, Y. Social entrepreneurship as emancipatory work. Journal of Business Venturing, v. 32, n. 6, p. 657-673, 2017.

CHEN, C. CiteSpace II: Detecting and visualizing emerging trends and transient patterns in scientific literature. JASIST, v, 57, n. 3, p. 359-377. 2006.

CHEN, C. Searching for intellectual turning points: Progressive knowledge domain visualization. PNAS, v. 101, p. 5303-5310. 2004.

CHOI, N.; MAJUMDAR, S. Social entrepreneurship as an essentially contested concept: Opening a new avenue for systematic future research. Journal of Business Venturing, v. 29, n. 3, p. 363-376, 2014.

DEES, J. Gregory et al. The meaning of social entrepreneurship. 1998.

FILION, L. J. Empreendedorismo: empreendedores e proprietários-gerentes de pequenos negócios. Revista de Administração da Universidade de São Paulo, v. 34, n. 2, 1999.

FISCHER, R. M.; COMINI, G. Sustainable development: from responsibility to entrepreneurship. Revista de Administração (São Paulo), v. 47, n. 3, p. 363-369, 2012.

GARCIA, A. S. Esferas públicas como uma categoria fundante da gestão social. 273p. (Mestrado em Administração) - Universidade Federal de Lavras, 2016.

GOMES, A. F.; DE LIMA, J. B.; CAPPELLE, M. C. A.. Do Empreendedorismo À Noção De Ações Empreendedoras: Reflexões Teóricas. Revista Alcance (Online), v. 20, n. 2, p. 203, 2013.

HULGÅRD, L.; VIEIRA FERRARINI, A.. Inovação social: rumo a uma mudança experimental na política pública?. Ciências Sociais Unisinos, v. 46, n. 3, 2010.

KING, C. Web of Science: 1 billion cited references and counting. 2017. Disponível em: <https://goo.gl/1HCEEJ>. Acesso em: 01 maio 2017.

LIU, W. et al. Profile of developments in biomass-based bioenergy research: a 20-year perspective. Scientometrics, v. 99, n. 2, p. 507-521, 2014.

MAIR, J.; MARTI, I.. Social entrepreneurship research: A source of explanation, prediction, and delight. Journal of world business, v. 41, n. 1, p. 36-44, 2006.

NICHOLLS, A.. The legitimacy of social entrepreneurship: reflexive isomorphism in a preparadigmatic field. Entrepreneurship theory and practice, v. 34, n. 4, p. 611-633, 2010.
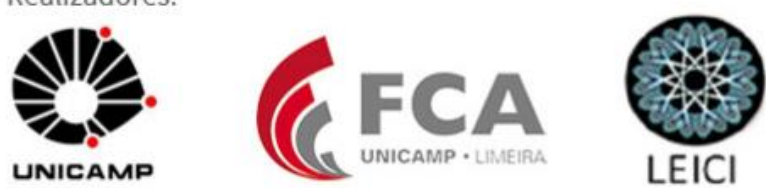
NICOLOPOULOU, K.. Social entrepreneurship between cross-currents: toward a framework for theoretical restructuring of the field. Journal of Small Business Management, v. 52, n. 4, p. 678-702, 2014.

OLIVEIRA, E. M.. Empreendedorismo social no Brasil: atual configuração, perspectivas e desafios-notas introdutórias. Revista da FAE, v. 7, n. 2, 2004

PARENTE, C. et al. Empreendedorismo social: contributos teóricos para a sua definição. In: XIV Encontro Nacional de Sociologia Industrial, das Organizações e do Trabalho Emprego e coesão social: da crise de regulação à hegemonia da globalização Lisboa, Anais...2011.

PEREDO, A. M.; MCLEAN, M.. Social entrepreneurship: A critical review of the concept. Journal of world business, v. 41, n. 1, p. 56-65, 2006.

PHILLIPS, W. et al. Social innovation and social entrepreneurship: A systematic review. Group \& Organization Management, v. 40, n. 3, p. 428-461, 2015.

PINTO, C. F.; SERRA, F. R.; FERREIRA, M. P.A bibliometric study on culture research in International Business.BAR, v. 11, n. 3, p. 340-363, 2014.

PRADO, J. W. et al. Multivariate analysis of credit risk and bankruptcy research data: a bibliometric study involving different knowledge fields (1968-2014). Scientometrics, v. 106, n. 3, p. 1007-1029, 2016.

QUINTÃO, C.. Empreendedorismo social e oportunidades de construção do próprio emprego. In: Seminário Trabalho Social e Mercado de Emprego. Universidade Fernando Pessoa 2004.

SANCHEZ-RIOFRIO, A. M.; GUERRAS-MARTIN, L. A.; FORCADELL, F. J. Business portfolio restructuring: a comprehensive bibliometric review. Scientometrics, v. 102, n. 3, p. 1921-1950, 2015.

SURIE, G.; GROEN, A.. The importance of social entrepreneurship in national systems of innovation-Anintroduction. 2017.

TENÓRIO, F. G.. (Re) visitando o conceito de gestão social. Desenvolvimento em questão, v. 3, n. 5, 2005.

TENÓRIO, F. G. Um espectro ronda o terceiro setor: o espectro do mercado. Revista de administração pública, v. 33, n. 5, p. 85-102, 1999.

THEOBALD, R. The Rapids Change: Social Entrepreneurship in Turbulent Times. 1998

WEERAWARDENA, J.; MORT, G. S.. Investigating social entrepreneurship: A multidimensional model. Journal of world business, v. 41, n. 1, p. 21-35, 2006.

YOUNG, Dennis R.; LECY, Jesse D. Defining the universe of social enterprise: Competing metaphors. VOLUNTAS: International Journal of Voluntary and Nonprofit Organizations, v. 25, n. 5, p. 1307-1332, 2014.

ZAHRA, S. A. et al. A typology of social entrepreneurs: Motives, search processes and ethical challenges. Journal of business venturing, v. 24, n. 5, p. 519-532, 2009.

SCHNEIDER, A. Social Entrepreneurship, Entrepreneurship, Collectivism, and Everything in Between: Prototypes and Continuous Dimensions. Public Administration Review, v. 77, n. 3, p. 421-431, 2017. 